\title{
El espectador y la identificación cinematográfica. Los niños del cielo de Majid Majidi como fondo
}

\section{The Spectator and Film Identification. Majid Majidi's Children of Heaven as a Background.}

\author{
Julio César Goyes Narváez (Colombia)
}

igoyesn@gmail.com

Universidad Nacional de Colombia

\section{Resumen}

Con la película "Los niños del cielo" como fondo, el autor analiza los procesos de apropiación del espectador y su identificación cinematográfica. De acuerdo con el texto, esta invita a que su público se identifique con los personajes, porque reúne temas como pobreza, la crítica al sistema dominante, la desigualdad, juventud, el heroísmo por superar el atraso socioeconómico, la crítica al racismo, entre muchos otros. Como muchas otras muestras del cine iraní, cuenta con una búsqueda estética que se acerca al Movimiento

\section{Abstract}

The autor analyzes the processes of the spectator appropriation and their film identification with the film Chldren of Heaven as a background. According to the text, the movie invites the audience to feel identified with the characters because it features topics such as poverty, criticism of the dominant system, inequality, youth, heroism to overcome socioeconomical backwardness, criticism of racism among many others. Like many other samples of the Irani film industry, it features an aesthetic pursuit that becomes close to that of the Institutional Representation Movement

\section{FECHA DE RECEPCIÓN: FECHA DE REVISIÓN: APROBACIÓN: \\ 2 de agosto de 20012 12 de octubre de 2012 16 de octubre de 2012}

Para Citar este artículo / to CITE this ARTICLE Goyes Naráez, J C. El espectador y la identificación cinematográfica. Los niños del cielo, de Majid Majidi como fondo. Poliantea, 8(15), $119-134$. 
de Representación Institucional (MRI). Goyes explica cómo muchas veces la visión del director, manejo de cámaras y guión están pensados para llevar al observador al "estadio del espejo", que introduce la noción de que el cine construye a su espectador. A su vez, responde preguntas como ¿jpor qué sufre el espectador con la historia? y ¿̇por qué una historia tan sencilla llama tanto nuestra atención? El autor demuestra que, dentro del cine, nada es coincidencia y que mientras los que lo desarrollan tengan la clave para narrar una historia, siempre existirá una identificación entre el filme y el espectador.

Palabras clave: espectador, cine iraní, Majid Majidi, Los niños del cielo.
(MRI) for its initials in Spanish. Goyes explains how in many opportunities the director's view, the camera work and the script are conceived to take the spectator to the "mirror stage" which introduces the notion that the film constructs its spectator. Likewise, he answers questions such as "Why does the spectator suffer with the story?" and "Why does such a simple story strike us so hard?" The author demonstrates that in films nothing is a coincidence and that as long as the producers have the key to narrate a story there will always be a connection between the film and the spectator.

Keywords: spectator, Irani film industry, Majid Majidi, Children of Heaven 


\title{
El espectador y la identificación cinematográfica. Los niños del cielo de Majid Majidi como fondo
}

\author{
Julio César Goyes Narváez (Colombia) \\ Docente investigador del Instituto de Estudios en Comunicación y \\ Cultura (IECO) de la Universidad Nacional de Colombia
}

La pelota que arrojé cuando jugaba en el parque aún no ha tocado el suelo.

Dylan Thomas

El epígrafe podría en principio desconcertar: ¿qué relación tienen los versos del poeta galés con la película que me ocupa? A parte de inscribir el punto de vista de quien escribe este texto, pues es uno de mis poetas preferidos, tiene su correlato en la forma como veo el cine de infancia. No, desde luego, el producido para niños o realizado por niños que tiene ya una honda repercusión en el panorama cinematográfico. Me interesa el cine sobre infancia hecho por adultos, pues, es en esta mirada, donde se ubica el poeta visual sobre el cual deseo hablar. Si hay algún motivo por el cual me conmueve la película del iraní Majid Majidi, es justamente el hecho de estar en esa abscisa escritural donde la creatividad es la infancia, o viceversa. Además, el filme Los niños del cielo (1997) mantiene al espectador en un estado de regresión donde la pelota, de la que habla Dylan Thomas, no cae todavía; diría que el espectador guarda una pelota en su inconsciente y sale a pivotear frente a la pantalla de cine cuando esta es convocada.

Sin el contrato tácito entre director-filme-espectador es difícil, por no decir imposible, que haya identificación con la narración cinematográfica. Si el director quiere que su mirada afecte al espectador de la misma 
manera que lo afectó a este, entonces hay que despertar en el espectador un estado anímico análogo al que experimentó el director en su encuentro real. Este fue uno de los postulados básicos para directores como Andrei Tarkovski, que no concibió otro cine que aquel que desata una dimensión emocional que comunica al director con el espectador. No obstante, "una obra de arte, en cualquier caso, supone la ligazón orgánica de idea y forma”. Un práctica vanguardista y posmoderna, sin duda, porque aunque el cine es el arte más realista, está destinado a emocionarnos por la belleza y profundidad de sus imágenes (2005, pp. 33-57).

La película de Majid Majidi la he visto varias veces y en épocas diferentes. Hago esta salvedad por cuanto lo que sigue atiene a percepciones diferentes según el contexto espacio-temporal, el punto de vista y el estado de ánimo. Es evidente, entonces, que de entrada me he ubicado en el sitio del espectador y con él en las teorías cinematográficas de la recepción y la experiencial.

1 Por un lado, está la teoría de lo imaginario, con Edgar Morin a la cabeza, como deriva hacia una antropología cinematográfica; por otro, la teoría de la recepción
La primera vez que vi Los niños del cielo (1997) estaba asistido por un contexto latinoamericano que gusta del cine iraní no por exótico, sino porque se hermana con el cine latinoamericano y español en algunos aspectos, quizás los más esenciales, desde luego, cada uno en su contexto: parecidas preocupaciones culturales por la infancia y la juventud, el heroísmo por superar el atraso socioeconómico, la incisiva defensa de la dignidad, la crítica al racismo, la pobreza como referente donde los protagonista crecen, las producciones de bajo presupuesto, la crítica disimulada al sistema

propiamente dicha, o mejor la estética de la recepción, aquella que ubica al espectador (lector-receptor, para la escuela de Constanza) en un "horizonte de expectativas", "indeterminación" y "espacio vacío" (Roman Ingarden), donde el lector (entiéndase espectador), mediante el proceso de "concreción", Ilena estos vacíos, determinando lo indeterminado, aunque siempre cabe la posibilidad de múltiples recepciones como espectadores y épocas históricas haya, tal como lo entiende autores como Robert Jauss o Wolfgang Iser. De allí que la obra de arte no solo sea el texto (filme) producido por el autor, sino el texto una vez transformado por el receptorespectador en obra. Hay, sin embargo, una tercera influencia: se trata del análisis textual, teoría interdisciplinaria que oscila entre la antropología, la semiótica y el psicoanálisis, liderada lúcidamente por Jesús González Requena y su grupo de Trama y Fondo de Madrid. Y aunque aquí no hacemos análisis textual en sentido estricto, nos apoyamos en su teoría y metodología. 
dominante bien nacional o global, y, sobre todo, la similar búsqueda estética que se acerca al Movimiento de Representación Institucional (MRI), entre otras razones, porque no es tanto la forma lo que se intenta mostrar o experimentar, sino la historia desde puntos de vista diversos (cfr. Archivos de la Filmote$c a, 1995) 2$. Este disimulo estetizante del filme se presenta a beneficio de una actitud conmovedora y, por defecto, crítica que incita al espectador a la toma de posición, tal como lo propuso el neorrealismo y el cine poético. El "nuevo" cine iraní ha alcanzado notables niveles con producciones más bien modestas, y esto a pesar de su tendencia moralizante, como bien lo señal Yves Thoraval: “[...] las películas para niños y jóvenes son un género especialmente

2 Movimiento de Representación Institucional (MRI) o modos de representación del cine clásico (MRC). Este concepto lo aportó Noël Bruch (1987) como resultado de la síntesis y caracterización de los rasgos configuradores del sistema de representación: efecto de transparencia que a la vez es un efecto diegético pleno y envolvente; el mundo ficcional propuesto ofrece coherencia interna, causalidad lineal, realismo psicológico y continuidad espacial y temporal. El espectador, entonces, se vería sumergido a través de una identificación con el punto de vista centrado, perspectivo, dinámico y ubicuo construido por la mirada de la cámara (cfr. .González, 2006, pp. 479-482). minado por el régimen...”3 Este aspecto entabla una diferencia sustancial con el cine latinoamericano, hindú o español, puesto que al mostrar los conflictos de la infancia, intentan no solo cuestionar a fondo la realidad social capitalista, hoy neoliberal y globalizante, sino, además, denuncia el régimen político, en ocasiones totalitario.

A modo de ejemplo, podemos citar las películas latinoamericanas Crónica de un niño solo (1965), de Leonardo Fabio; Machuca (2004), de Andrés Wood; La vendedora de rosas (1998), de Víctor Gaviria; Los niños invisibles (2001), de Lisandro Duque; Los colores de las montaña (2010), de Carlos César Arbeláez; Los olvidados

3 Reseño como relevante, para argumentar el parecido de las cinematografías, en este caso la de un español y un iraní, el diálogo que se mantuvo entre Víctor Erice y Abbas Kiarostami con motivo de la Exposición Correspondencias, en el Centro de Cultura Contemporánea de Barcelona (CCCB), entre febrero y mayo de 2006. Los diálogos fueron conducidos por el crítico francés Alain Bergala, que sostiene que en el cine de los dos directores se asemejan puntos de enlace: la necesidad de mostrar el dispositivo cinematográfico, el alejamiento de la leyes industriales del cine, los paisajes pictóricos, el tema del silencio, la meditación, la infancia y el hecho de que los protagonistas sean niños, el mundo de los adultos incomprensible que es preciso cambiar y la necesidad de volver a educar al espectador desde la mirada de la infancia (cfr. Academia. Revista del Cine Español, marzo de 2006, p. 8). 
(1950), de Luis Buñuel; De la infancia (2009), de Carlos Carrera (estas dos últimas mexicanas), entre otros títulos y autores que han producido películas urbanas donde los niños se encuentran atrapados por la descomposición social, la crisis de la familia y la marginación del Estado. En el cine iraní, iraquí e hindú podemos citar, a modo de ejemplo: Donde está la casa de mi amigo (1987); $Y$ la vida continúa (1992); A través de los olivos (1994), de Abbas Kiarostami; Salam Bombay (1988), de Mira Nair; El color del paraíso (1999), de Majid Majidi, entre muchas otras. Es interesante también incluir películas españolas de gran acogida en Suramérica, especialmente en Colombia, como El Bola (2000), de Achero Mañas; Secretos del corazón (1997), de Montxo Armendáriz; La lengua de las mariposas (1999), de José Luis Cuerda, y más atrás películas emblemáticas como Cría cuervos (1976), de Saura y El espíritu de la colmena (1973), de Víctor Erice, para no citar sino algunas. Otra cosa es que esos elementos cinematográficos que relacionan a una y otra película, a uno y otro país, a uno y otro continente, alcancen la misma factura y los mismos resultados, pero esto es otro tema del que no me ocuparé aquí.
Experimentar con las expresiones formales - artísticamente hablandoequivale en contextos estigmatizados por el subdesarrollo a proclamar revoluciones sin saber por qué han de hacerse. Tal vez esta es una de las razones ideológicas más fuertes por las cuales un sector del cine latinoamericano y oriental se mantiene a buen recaudo del modo de representación institucional. Entiéndase bien lo que digo, no es que no haya propuesta formal, sino que esta se camufla o subyuga a la fábula, al contenido narrativo, al discurso cinematográfico, a los caracteres psicológicos de los personajes y a sus situaciones, tal como lo propone Cristian Metz, cuando observa la identificación cinematográfica secundaria como fase del espejo en el terreno individual. Es decir que hay una identificación emocional del espectador con alguno o varios de los personajes. Según Lacan el niño se identifica con la imagen primordial de su madre para formar su yo. Esta imagen primaria es la matriz del yo ideal, a partir de aquí es literalmente originaria y fundadora de la serie de identificaciones que lo seguirán luego e irán constituyendo el yo del ser humano. De suerte que el cine, al proyectar en la pantalla imágenes, sería un dispositivo para la regresión al estadio del espejo. Lo 
interesante es que, a la vez que originaria, esa primera identificación es alienante, puesto que se reconoce en lo que no es él mismo sino otro; además, ese otro, aunque fuese él mismo, está afectado por la simetría especular, condición que luego se reproducirá en los sueños; y aquel que se reconoce como yo (imagen) no tiene las limitaciones y problemas que el yo (real) tiene, por ejemplo, para moverse (cfr. Lacan, 2008).

En las películas de ficción clásicas, se borra deliberadamente al sujeto de la enunciación (las miradas a la cámara) para que la película funcione como historia (y no como discurso) y el espectador sienta que es él quien tiene que ocupar el lugar del sujeto de la enunciación. La película por el modo en que está construida, y por la presión que está ejerciendo el dispositivo técnico (a través de la identificación con la cámara), hace que el espectador sienta que él es el que está viendo esas imágenes como si no existiera ninguna instancia de mediación. El espectador se siente sujeto de la enunciación, en calidad de sujeto con pura capacidad de oír y ver.

Digamos, de paso, que el punto de quiebre con el MRI en estas nuevas producciones está en que, si bien el espectador logra identificarse con el punto de vista de la cámara o del director, con los personajes Ali o Sahara, incluso con los actores que representan esos personajes, dependiendo de la función que cada uno cumpla en el relato, lo hace como sujeto que sabe que lo que está viendo no es su imagen sino la de otros con la cual se identifica. Pero, además, y esto es importante para observar los matices con el MRI, existe una serie de prácticas sociales o condicionamientos del uso del dispositivo cinematográfico que están pensadas para colocar al espectador en una determinada posición, la del "estadio del espejo", que introduce la noción de que el cine construye a su espectador. Si esto es así, la sociedad cinematográfica con sus restricciones sociales que afectan al consumo, y en el caso que me ocupa, la iraní, hindú, colombiana, argentina, chilena, mexicana, española, etc., construirían espectadores diferentes a otras cinematografías, más centradas en el espectáculo, la ficción pura o el documental tradicional (cfr. Casetti, 1994, cap. X, p.165.; Aumont y Bergala, 2002, cap. 5 , p 221, numeral 3, hablan de la doble identificación en el cine).

He sugerido, entonces, que la película Los niños del cielo está más 
cerca al filme clásico que al experimentalismo posmoderno, y sin embargo, es un filme posmoderno o posclásico, si por esto entendemos el retorno revisado a los viejos temas y problemas que el cine se ha planteado desde su origen, con la diferencia de que, por un lado, hay una tensión cinematográfica que, desde lo local, se abre a lo global, y por otro, la inclusión de nuevos actores y escenarios: el punto de vista del melodrama de la infancia lo postula la mirada infantil del director, que es un adulto; además, la historia la encarnan actores que son niños, aunque estén dirigidos por un adulto. A esta altura, el epígrafe del comienzo toma sentido, pues también para el director Majid Majidi la pelota del parque no ha tocado el suelo. De todo esto resulta que podría dedicarle algunos párrafos a varios aspectos de la película; no obstante, intentaré anclar en aquellos que la aproximan demasiado al MRI, algo sin duda esencial en este filme: la estructura actancial del relato.

Aspectos importantes por interrogar son por ejemplo: por qué sufre el espectador con la historia, sobre todo con las escenas en que vemos correr, por entre caños de agua constantemente a Ali y a
Sahara evitando llegar tarde a la escuela. El director le ha informado a Ali que si lo hace de nuevo lo expulsa; la intervención de su profesor logra que el espectador se reconcilie con la justicia y tome partido por la educación. Y qué decir del final glorioso de la prueba de atletismo, mientras su entrenador e inspector gozan con el triunfo; Ali (y el espectador cómplice) sufre, pues el premio de los zapatos era únicamente para el segundo lugar. ¿Por qué los zapatos de Sahara son rojos y los de Ali son blancos? ¿Qué información comporta los canales de agua, la pila, los peces? Lo propio ocurre con el padre de Ali, que lo vemos en un comienzo demasiado severo, luego relaja nuestro disgusto por la manera como se comporta con Ali al llevarlo a la ciudad en bicicleta y querer mostrarle cómo funciona la vida urbana; no obstante, descubrimos que el padre de Ali es tímido y tiene miedo, queda así humanizado ante la mirada de su hijo y ante la del espectador, etc.

Digamos con Christian Metz, que la identificación secundaria que padece el espectador no es posible sin la "identificación cinematográfica primaria”, aquella por la cual el espectador se identifica con su propia 
mirada y se experimenta a sí mismo como representación privilegiada. Este privilegio tiene que ver con esa atmósfera poética que captura desde el primer plano Los niños del cielo. Identificación, por otra parte, que está en el ojo de la cámara que oculta a su vez al sujeto de la visión y su punto de vista exclusivo. Esta identificación es inmediata a cuenta de saber - con disimulo- que el director es quien nos hace ver eso que el espectador está viendo. El espectador, de algún modo, sospecha que varias cosas que va a ver, cada vez que asiste a un filme, son las mismas de siempre, y sin embargo "finge" no recordarlas, pues le conviene porque de alguna manera sabe y no sabe lo que va a visionar. Por un lado, "finge" saber para poder gozar del relato, mas hay algo que realmente el espectador no sabe, y eso que no sabe está en el orden del inconsciente. O para decirlo en palabras de Jesús González Requena, "lo que nuestro inconsciente reconoce es algo que nuestra conciencia no sabe" (1999, p. 116). Lo que resulta de allí es la ovación espontánea del espectador que ha caído en la trampa del sujeto trascendental de la visión que todo lo percibe: "ese director es un poeta", o "la película es muy poética" o, finalmente, "ese director tiene una sensibilidad muy especial", "qué maravilla hacer esa película con tan pocos elementos", etc. 4

Esta identificación primordial tiene que ver con el hecho narrativo mismo, independiente de la forma y la materia de expresión, pues, esta atracción hacia lo narrativo se constituye desde la infancia. Tal aspecto filogenético y ontogénico ha sido trabajado con rigor desde la óptica de la etnografía y el psicoanálisis por investigadores, como Bruno Bettelheim (Psicoanálisis de los cuentos de hadas, 1988) y Gianni Rodari (La gramática de la fantasía, 1992), para solo citar dos conocidos5. Y si los traigo a colación es por

4 Christian Metz propone reservar la "identificación primaria" a la fase preedípica de la historia del sujeto y llamar "identificación cinematográfica primaria" a la del espectador con sus propia mirada (cfr. Aumont y Bergala, 2002, pp. 263-264).

5 Bruno Bettelheim en Psicoanálisis y cuentos de hadas ha mostrado cómo el escenario fantástico de los cuentos de hadas (podríamos decir de los cuentos infantiles en general) es el espacio para hacerles frente a conflictos que en la realidad se muestran dramáticos y, en algunos casos, aterradores. El caso de Gianni Rodari es diferente, más del lado creativo, sin embargo, parte de los mismo supuestos: al conocer la estructura actancial del relato, un sujeto - preferiblemente un niño pero no necesariamente- puede crear historias múltiples y, por lo tanto, hacer catarsis de diferentes modos. En este sentido, la identificación no sería en la superficie del imaginario, 
la importancia que tiene para la infancia la estructura actancial del relato (llámese mito, cuento, leyenda, novela, cine, teatro, poesía, etc.). Es decir que los niños, los hombres primitivos y los actuales, en lo más arcaico de su subjetividad y función simbólica, recurren a este suceder de acción como constante en la búsqueda de la homeostasis histórica. De razón, Edgar Morin afirmaba la relación imaginaria del cine no únicamente con el sueño, sino también con una cualidad antropológica compleja y arcaica del hombre, rechazada por el logicismo positivista: la magia. De allí que el cine como maquinaria moderna pero al tiempo ancestral permite fotografiarnos a nosotros mismos hasta convertirse en "archivo de almas" (cfr. Casetti, 1994, cap. III, pp. 55-65).

La estructura fundamental del relato es análoga a la estructura edípica. De allí que "todo relato clásico inicia la captación de su espectador al ahondar la separación inicial

al decir de Jesús González Requena, "ingenuidad según la cual el espectador se identificaría con el personaje", sino en el orden narrativo puramente simbólico, pues, "la identificación es de orden inconsciente y no debe ser confundid[a] con ciertos epifenómenos que alcanzan la conciencia". De suerte que identificación y empatía no son coincidentes (1999, p. 117). entre sujeto deseante y objeto de deseo" (Aumont y Bergala, 2002, p. 267). Entre uno y otro hay un proceso que dificulta o posibilita que uno (deseante) obtenga lo otro (deseo). La narración clásica en la que se mueve la película de Majid Majidi, por ejemplo, reconoce estas situaciones de equilibrio: al inicio se tiene pero se pierde (los zapatos rojos de Sahara) y al final se vuelve a obtener (los zapatos rojos de Sahara), restituyendo así la carencia primordial del relato y obteniendo un valor agregado: los zapatos blancos de Ali y la gloria atlética del héroe.

Aumont y Bergala (2002) plantean que el equilibrio narrativo clásico se logra a cuenta de una serie de dificultades, falsas pistas, contratiempos, debido a la bondad o maldad humana, pero cuya función narrativa es mantener el deseo del espectador atento esperando ver la solución y la forma en que termina el relato. Seguramente, el espectador de Los niños del cielo se preguntará: ¿por qué una historia tan sencilla llama tanto nuestra atención? La respuesta está a varios niveles, no obstante, veamos dos: por un 
lado, el proceso de desequilibrio y restitución de ese equilibrio se da a partir de una serie de roles actanciales y programas narrativos bien definidos; por otro, cada personaje y cada objeto unido a ese personaje posee una carga simbólica que sustrae la subjetividad del espectador y lo vuelve participativo hasta la tensión. Al final, la angustia que padece el espectador se relaja de una manera poética, pues, la metáfora visual es contundente: dentro de un pila con agua clara vemos los pies de Ali ulcerados por el esfuerzo al que fueron sometidos, varios peces rojos (como los zapatos de Sahara) parecen besarlos, o por lo menos transmitirles ternura, alivio. Una especie de purgación natural y de recompensa al mismo tiempo por los actos heroicos del niño, pues jamás doblegó el deseo de recuperar para su hermana los zapatos perdidos. El punto de vista dentro del agua es importante para la regresión y participación plena del espectador. De esta forma sutil e inconsciente por lo simbólica, restituye también, para el espectador, el objeto perdido pero constantemente deseado: la dignidad sexual de su hermana.

En el primer caso, el de los roles actanciales y programas narrativos, invocamos los estudios de Vladimir Propp y A. J. Greimas. Citemos al segundo que hizo de la propuesta del primero un compendio sintético y fundamental de la estructura semántica con la cual la narratología y la semiótica se operativizaron discursivamente. De suerte que Greimas construyó un modelo actancial, cuyos códigos narrativos se basan en el enfrentamiento entre el deseo y la ley (la prohibición). El modelo actancial permite ser reconstruido de varias formas, teniendo en cuenta diferentes programas o microprogramas narrativos: un sujeto puede a su vez ser objeto de deseo, incluso ayudante u oponente de otro actor y otra acción; así, en todas las combinaciones posibles. Aquí nos ocupamos únicamente del que creemos es el macroproyecto narrativo principal del filme Los niños del cielo: 


\begin{tabular}{|l|l|l|}
\hline $\begin{array}{l}\text { Sujeto } \\
\text { (Héroe-Ali). Preservar } \\
\text { la tradición como hermano } \\
\text { y como hombre. }\end{array}$ & $\begin{array}{l}\text { Eje-deseo } \\
\text { La sexualidad } \\
\text { de la mujer o del hombre, según desde } \\
\text { dónde construyamos el modelo actancial. }\end{array}$ & $\begin{array}{l}\text { Objeto } \\
\text { (Zapatos rojos } \\
\text { para Sahara, su hermana). } \\
\text { La dignidad femenina: } \\
\text { su sexualidad. }\end{array}$ \\
\hline $\begin{array}{l}\text { Destinador } \\
\text { (Alguien que fija la misión: el "superyó" de } \\
\text { Ali: la cultura y su axiología). }\end{array}$ & $\begin{array}{l}\text { Eje-ley } \\
\text { Cuidar la sexualidad } \\
\text { de la hermana: preservar } \\
\text { la dignidad familiar. Virginidad/incesto. }\end{array}$ & $\begin{array}{l}\text { Destinatario } \\
\text { (El que recoge el fruto: Sahara y Ali. La } \\
\text { cultura iraní, las culturas universales). }\end{array}$ \\
\hline $\begin{array}{l}\text { Ayudante } \\
\text { (Sahara-profesor-padre de } \\
\text { Ali-entrenador). }\end{array}$ & $\begin{array}{l}\text { Eje-realización } \\
\text { del deseo } \\
\text { Dificultades y compleidad. } \\
\text { Tradición/modernidad. }\end{array}$ & $\begin{array}{l}\text { Oponente } \\
\text { (Tendero-inspector- padre en un momento- } \\
\text { hombre de la carretilla-niña que se pone } \\
\text { los zapatos-niños atletas, uno en especial- } \\
\text { entrenador en un primer momento). }\end{array}$ \\
\hline
\end{tabular}

La historia del niño que pierde por accidente (diríamos inconsciente) los zapatos rojos remendados de su hermana Sahara tiene una estructura narrativa clara y operativa: Ali que tuvo los zapatos rojos en sus manos los pierde, a partir de allí busca desesperadamente ese objeto valioso para su hermana (macroprograma); al tiempo que lo hace y pasa por varias pruebas (corre todo el tiempo) se prepara para lograr también su propia consagración como atleta, como heraldo del esfuerzo y la lucha (microprograma). Resulta que eso que intenta restituir como pérdida para su hermana es la dignidad frente a la escuela como espacio social, pero también esos zapatos simbolizan el amparo de la ley con respecto a la sexualidad de su hermana, prolongando como hermano, y como hombre en potencia, la tradición familiar y la ideología religiosa del pueblo iraní con respecto a la sexualidad femenina. No en vano el premio para Ali por triunfar en la carrera atlética es zapatos blancos, de ningún otro color. En resumidas cuentas, es la ley de cualquier pueblo, cuyos valores estén sostenidos en la virginidad, la inocencia y la dignidad. Hemos tenido noticias del precio que ha tenido que pagar la mujer ante estos valores tradicionales, bien por sostenerlos o bien por haberlos perdido. Esta lectura la hago pensando un poco en los cuentos infantiles, sobre todo en aquellos relatos donde la zapatilla roja inscribe un juego simbólico de la sexualidad desde tiempos inmemoriales. El símbolo de dignidad lo reelaboro de la antropología 
de los pies descalzos: pueden los zapatos estar remendados, retocados, restituidos las veces que sea posible, pero no se puede andar sin ellos.

Notemos que, en el filme de Majid, hay escenas significativas a este respecto que parecieran no dejar ninguna duda; desde luego que el director no tuvo que hacer ningún esfuerzo al montarlas, pues hacen parte de la cotidianidad de su cultura. Tomemos, por ejemplo, las escenas de la casa, cuando los chicos entran y dejan los zapatos afuera en las escaleras, o aquella otra crucial en la que Ali, su papá y un amigo, van al templo y reparten el té. Como en todo espacio religioso y oratorio musulmán, los zapatos se quedan afuera, pues el contacto con el templo sea hace sin ellos, lo sagrado no tiene mediación, tierra y cielo por un instante parecen unirse, pero esto únicamente ocurre en estos dos espacios. Fuera del templo y fuera de la casa hay que llevar los zapatos puestos. Si se camina por las calles y se va a la escuela sin zapatos se estaría faltando a la ley tradicional. Sencillamente, no se lo permiten.

Concluyamos, entonces, que la película de Majid Majidi está muy ligada a la narración clásica, y por ello mismo captura la atención del espectador que se identifica inmediatamente con el relato y su dinámica de oposiciones (héroeprincesa-malos-buenos) y por los programas narrativos de cada actante: Ali, buen hermano, héroe fuerte y combativo, aun con escasa alimentación; Sahara, buena hija atiende como su madre a la familia, necesita de sus zapatos rojos para ir a la escuela, quiere ir digna y no avergonzarse; los hermanos, a pesar de su humildad, son excelentes estudiantes; el padre es buen padre a pesar de su pobreza, es altivo, justo, cariñoso y religioso; la madre, aunque enferma, es valiente y se preocupada por su familia sin cesar. Al mismo tiempo, el espectador queda capturado por el imaginario-espejo que le devuelven los personajes infantiles, Ali para los hombres, Sahara para las mujeres, o los dos simultáneamente, si atendemos en el nivel simbólico la ambigüedad que comporta el complejo de Edipo en la identificación.

Las imágenes tanto dicen como ocultan el hecho mismo de que aún en la pobreza y las grandes dificultades de la vida es preciso sobreponerse, luchar y llegar donde se quiere sin entregar la dignidad; se supone que, en este caso, equivale a valores religiosos que tienen que ver 
directamente con la sexualidad. ¿ $\mathrm{No}$ remite esto al consejo eterno de un padre a sus hijos?, ¿el continuo palabreo de un adulto a los menores? El círculo queda cerrado: los niños con todas las dificultades están o siguen estando en el cielo, siempre y cuando se transite por los roles actanciales y la axiología que hemos leído. En la actualidad, los roles que cumplen los jóvenes con respecto a su sexualidad están trastocados, la dignidad y con ella los valores virginales se han escondido o, si se quiere, han desparecido. Deseo hacer notar un detalle que me parece relevante porque sugiere una interrogación muy pertinente hoy: curioso filme sobre los zapatos en un momento en el que los niños y los jóvenes están alienados por un consumo de marcas que miden el grado de prestigio. Podríamos decir: qué zapatos llevas, de qué marca y te diré quién eres. La publicidad insiste en que por los zapatos se sabe la personalidad del que los calza; nada distinto a la tradición, aunque en esta no hay dinero ni marca, sino pulcritud y aseo. Esto también recuerda a los padres, directores de disciplina y militares, que revisan los zapatos que no están limpios y brillantes; no hacen otra cosa que retrotraer la máxima popular: "los zapatos deben brillar de suerte que se vea el rostro reflejado en ellos", pero, aunque es real por la moral como por la limpieza que contiene, sigue siendo metafórico y no un ícono de desecho.

La pelota, entonces, no caerá jamás al piso, porque el cine continúa interpelando al espectador para que su esfera de infancia esté en vilo, cuestionada: garantía de un verdadero contrato cinematográfico de regresión entre el filme y el espectador. Mientras la pelota siga suspendida tenemos la esperanza de que no todo está perdido.

\section{Referencias}

Aumont, J. y Bergala, A. (2002). Estética del cine. Barcelona: Paidós.

Bruch, N. (1987). El tragaluz del infinito. Madrid: Cátedra.

Casetti, F. (1994). Teorías del cine. Madrid: Cátedra.

González Requena, J. (2006). Clásico, manierista, posclásico. Los modos del relato en el cine de Hollywood. Valladolid: Castilla ediciones.

González Requena, J. (1999). El discurso televisivo: espectáculo de la posmodernidad. Madrid: Cátedra. 
Lacan, J. (2008). El estadio del espejo. Escritos I. Siglo XXI

Tarkovski, A. (2005). Esculpir en el tiempo (7. a ed.). Madrid, Rialp.

VV. AA. (2006, marzo). La mirada sostenida y del diálogo entre Erice y Kiarostami. Academia. Revista del Cine Español, 121.

VV.AA. (1995, febrero). El nuevo cine iraní: héroe positivo y tentación estética. Archivos de la Filmoteca, 19, 6-21. 